\title{
O Uso do Ensino Híbrido nas Ciências: Mapeamento de Pesquisas no Portal de Periódicos da CAPES
}

\author{
El Uso de la Enseñanza Híbrida en las Ciencias: Mapeo de \\ Investigaciones en el Portal de Periódicos de la CAPES
}

\author{
The Use of Hybrid Science Teaching: Mapping of Researches in the Portal \\ of Periodicals of CAPES
}

\author{
Alessandro da Silva Saadi ${ }^{1}$ \\ Celiane Costa Machado
}

\begin{abstract}
Resumo
O presente artigo tem por objetivo realizar um mapeamento acerca do tema Ensino Híbrido nas Ciências e é parte preliminar de uma pesquisa de doutorado desenvolvida no Programa de Pós-Graduação em Educação em Ciências: Química da Vida e Saúde da Universidade Federal do Rio Grande - FURG- Este estudo é de cunho exploratório e de natureza bibliográfica. A busca foi feita no Portal de Periódicos da Capes, utilizando-se o descritor "Ensino Híbrido". Foram recuperados 30 trabalhos e após aplicar o filtro data de publicação (20132018), totalizaram 22 artigos. Após essa seleção, foi feita a leitura dos resumos dos mesmos, os quais foram descartados 18 artigos por não tratar da temática. A análise dos quatro artigos selecionados mostrou que a utilização do ensino híbrido pode contribuir para uma liberdade de escolha por parte dos estudantes na construção de seu conhecimento, que as aulas com apoio das tecnologias digitais oferecem uma nova maneira de ensinar e aprender, além de reforçar a necessidade de integrar a teoria e a prática. Entretanto, um dos trabalhos apontou que, para uma maioria de estudantes, o uso de tecnologias digitais não se faz necessária para a compreensão dos conteúdos de Física.

Palavras-Chave: Ciências; Ensino Híbrido; Portal de Periódicos da Capes
\end{abstract}

\section{Resumen}

El presente artículo tiene por objetivo realizar un mapeo sobre el tema Enseñanza Híbrida en las Ciencias y es parte preliminar de una investigación de doctorado desarrollada en el Programa de Postgrado en Educación en Ciencias: Química de la Vida y Salud de la Universidade Federal de Rio Grande - FURG. Este estudio es de cuño exploratorio y de naturaleza bibliográfica. La búsqueda fue hecha en el Portal de Periódicos de la Capes, utilizando el descriptor "Enseñanza Híbrido". Se recuperaron 30 trabajos y después de aplicar el filtro fecha de publicación (2013-2018), totalizaron 22 artículos. Después de esa selección, se hizo la lectura de los resúmenes de los mismos donde fueron descartados 18 artículos por no tratar de la temática. El análisis de los cuatro artículos seleccionados mostró que la utilización de la enseñanza híbrida puede contribuir a una libertad de elección por parte de los estudiantes en la construcción de su conocimiento, que las clases con apoyo de las tecnologías digitales ofrecen una nueva manera de enseñar y aprender, además reforzar la necesidad de integrar la teoría y la práctica. Sin embargo, uno de los trabajos apuntó que, para una mayoría de estudiantes, el uso de tecnologías digitales no se hace necesaria para la comprensión de los contenidos de Física.

Palabras Clave: ciencias; Enseñanza Híbrida; Portal de Periódicos de Capes

\footnotetext{
${ }^{1}$ Mestre em Matemática; Universidade Federal do Rio Grande - FURG; Rio Grande, Rio Grande do Sul e Brasil; alessandrosaadi@furg.br

${ }^{2}$ Doutora em Matemática Aplicada; Universidade Federal do Rio Grande - FURG; Rio Grande, Rio Grande do Sul e Brasil; celianemachado@ furg.br.
} 


\begin{abstract}
This article aims to map the theme Hybrid Science Teaching and is a preliminary part of a doctoral research developed in the Postgraduate Program in Science Education: Chemistry of Life and Health of the Universidade Federal de Rio Grande - FURG. This is an exploratory and bibliographical study. The search was done in the Portal of Periodicals of Capes, using the descriptor "Teaching Hybrid". Thirty papers were retrieved and after applying the filter date of publication (2013-2018), there were 22 articles. After this selection, it was read the summaries of the same ones where 18 articles were discarded for not dealing with the theme. The analysis of the four selected articles showed that the use of hybrid teaching can contribute to students' freedom of choice in the construction of their knowledge, that classes supported by digital technologies offer a new way of teaching and learning, besides reinforce the need to integrate theory and practice. However, one of the studies pointed out that, for a majority of students, the use of digital technologies is not necessary for understanding the contents of Physics.
\end{abstract}

Keywords: Sciences; Hybrid Teaching; Capes Newspaper Portal

\title{
1. Introdução
}

O presente artigo trata de um mapeamento no Portal de Periódicos da Coordenação de Aperfeiçoamento de Pessoal de Nível Superior (CAPES), sobre o tema Ensino Híbrido nas Ciências. Esse trabalho é parte inicial de um projeto de pesquisa de doutorado desenvolvido no Programa de Pós-Graduação em Educação em Ciências: Química da Vida e Saúde PPGEC, da Universidade Federal do Rio Grande - FURG.

A trajetória dos autores na área da Matemática, em especial, do Cálculo, instigaram o interesse por questões de retenção e evasão nas disciplinas básicas na área de Matemática nos cursos ofertados na FURG. Assim, surgiu a ideia de oferecer aos estudantes da FURG um curso de Pré-Cálculo utilizando as metodologias ativas, em especial, o Ensino Híbrido ou Blended. De acordo com Horn e Staker o ensino híbrido

é um programa de educação formal, no qual um estudante aprende, pelo menos em parte, por meio de aprendizagem on-line, sobre o qual tem algum tipo de controle em relação ao tempo, ao lugar, ao caminho e/ou ao ritmo e, pelo menos em parte, em um local físico, supervisionado, longe de casa. As modalidades, ao longo do caminho de aprendizagem de cada estudante em um curso ou uma disciplina, estão conectadas para fornecer uma experiência de aprendizagem integrada (HORN e STAKER, 2015, p. 54).

Desta forma, o objetivo desse trabalho consiste em mapear as produções referentes ao uso do Ensino Híbrido na área das Ciências, visto a intenção de avançar os estudos, investigando a colaboração do curso de Pré-Cálculo Blended na aprendizagem da disciplina de Cálculo.

\section{O Ensino Híbrido}


O termo híbrido, em sua definição literal, significa misturado. Horn e Staker (2015) apresentam a definição de ensino híbrido, com base em três partes: por meio do ensino online, num local físico supervisionado e com uma experiência de aprendizagem integrada, ou seja, as partes online e presencial devem atuar juntas para propiciar um curso integrado. A organização dos modelos de Ensino Híbrido proposta pelos autores é apresentada na Figura 1.

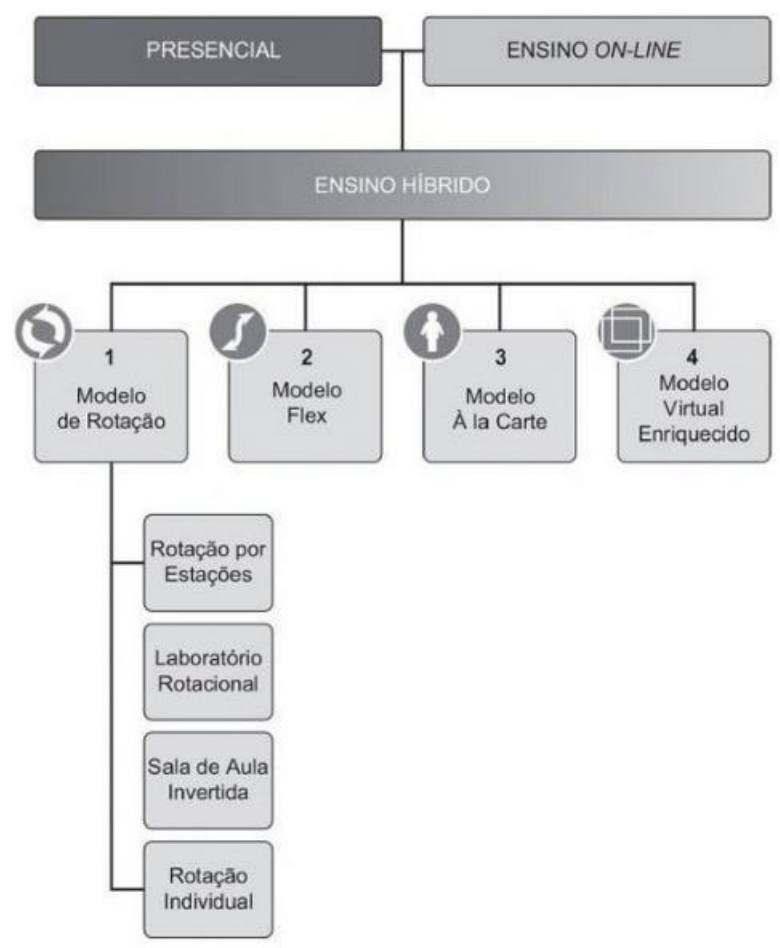

Figura 1- Modelos de Ensino Híbrido

Fonte: (HORN; STAKER, 2015)

Contudo, a sistemática referente aos modelos de Ensino Híbrido definidas por Horn e Staker (2015) está em constante evolução. Os autores destacam os seguinte tipos de programas vistos na Educação Básica de diversos países: Modelo de Rotação, Modelo Flex, Modelo À la Carte e Modelo Virtual Enriquecido.

O Modelo de Rotação consiste em um curso onde os estudantes intercalam diferentes modalidades de aprendizagem em um plano de atividades fixo ou a critério do professor, no qual pelo menos uma delas é ensino online. Os estudantes aprendem basicamente em um ambiente físico, exceto por alguma lição de casa (HORN; STAKER, 2015). Esse modelo é subdividido em Rotação por Estações, Laboratórios Rotacionais, Sala de Aula Invertida e Rotação Individual.

No modelo Rotação por Estações, os estudantes utilizam o modelo de rotação em uma sala de aula ou grupo de salas de aula, onde pelo menos uma das estações emprega os 
recursos de ensino online. No modelo Laboratório Rotacional, os estudantes alternam entre aprendizagem presencial e o laboratório de informática, que serve de estação de ensino online. Já na Sala de Aula Invertida os estudantes têm ensino online fora da sala de aula, no lugar da lição tradicional, eles frequentam a escola física para desenvolver atividades orientadas por um professor, sendo o ensino online a principal fonte de conteúdo. No modelo Rotação Individual, é disponibilizado ao estudante um plano de atividades individual, sem necessariamente alternar para cada estação ou modalidade disponível. Nesse caso, um software ou professor(es) definem os planos de atividades individuais de cada aluno (HORN; STAKER, 2015).

O Modelo Flex é um curso ou disciplina em que o ensino online é a base para a aprendizagem do estudante, embora ele desenvolva atividades presenciais, em que os mesmos aprendem por meio de plano de atividades personalizado entre as modalidades de aprendizagem. Neste caso, o professor da disciplina é presencial, ou seja, os estudantes aprendem principalmente na escola física, exceto por alguma lição de casa. Além disso, recebem apoio do professor ou de outros adultos, em uma base flexível e adaptada. (HORN; STAKER, 2015).

No Modelo À la Carte, o curso é inteiramente online e neste modelo, o professor também atua online. Esse modelo se diferencia do ensino online em tempo integral pois não é uma ação de toda a escola. Já no Modelo Virtual Enriquecido, os estudantes têm momentos de aprendizagem presenciais obrigatórios com o professor, ficando livre para completar o curso de forma distante do professor presencial. Neste modelo, o ensino online é a base da aprendizagem quando os estudantes estão em locais distantes (HORN; STAKER, 2015).

\section{O Mapeamento e Discussão dos Resultados}

O mapa teórico é uma metodologia que tem seus procedimentos organizados em três etapas: identificação, classificação/organização e reconhecimento/análise (BIEMBENGUT, 2008). Segundo a autora o mapa teórico:

não se restringe a um mero levantamento e organização de dados, e tampouco ao traçado de um mapa. É um forte constituinte não somente para reconhecimento ou análise dos dados, mas, especialmente, por proporcionar um vasto domínio sobre o conhecimento existente da área investigada. Suscita-nos desenvolver fórmulas ou meios adequados para compreensão, análise e representação dos dados ou das informações investigadas e conhecer as questões que envolvem as ações educacionais ou pedagógicas à medida que essas questões se revelem ou revelem movimentos resultantes das circunstâncias. (BIEMBENGUT, 2008, p. 90) 
Primeiramente, definiu-se o Portal de Periódicos da CAPES como locus para a coleta de dados deste estudo, visto a importância que o mesmo tem para a pesquisa brasileira. A seguir, realizou-se um levantamento exploratório no portal, que é atualizado constantemente. Por isso, definiu-se como data limite para essa pesquisa o ano de 2018.

Ingressou-se no Portal de Periódicos da CAPES por meio do Acesso Comunidade Acadêmica Federada (CAFe) com a identificação da instituição de ensino a qual pertencem os autores dessa pesquisa, com login e senha do sistema da FURG. Para mapear o tema da pesquisa, utilizou-se como descritor o termo "Ensino Híbrido", obtendo como resultado 30 trabalhos. Aplicamos o filtro "data de publicação", que foi de 2013 a 2018, onde recuperamos 22 artigos.

Após selecionar os 22 artigos, os resumos foram organizados em um único documento, para a identificação daqueles que tinham relação com a área do Ensino Híbrido nas Ciências. Para Biembengut,

\begin{abstract}
feita esta primeira identificação, lemos os resumos das produções e, então, efetuamos seleção e classificação, organizando-os na forma de catálogo, rol ou descrição pormenorizada. Se o número de pesquisas levantado for muito grande, faremos uma primeira seleção segundo pressupostos que indiquem os relevantes para apoiar ou fundar o problema da pesquisa. Quanto mais resumos tomarmos para uma primeira inteiração com o tema, melhores condições reuniremos para escolher os que sustentarão nossa pesquisa e comporão nosso mapa. (BIEMBENGUT, 2008, p. 91)
\end{abstract}

Após essa seleção, feita a leitura dos resumos, a etapa de classificação/organização do mapa teórico evidenciou quatro pesquisas na área de Ensino Híbrido nas Ciências, sendo, portanto, descartados 18 artigos por se tratar da temática Ensino Híbrido em outros contextos como por exemplo: o Ensino Híbrido no ensino de línguas estrangeiras, o Ensino Híbrido no ensino de Direito, abordagem do Ensino Híbrido de uma forma mais geral sem aplicação na Ciências e resenhas de livro sobre conteúdo relativo ao Ensino Híbrido. Dessa forma o corpus do trabalho ficou constituído por quatro artigos, conforme apresentado na Tabela 1.

Tabela 1- Corpus da Pesquisa

\begin{tabular}{c|c|c|c}
\hline Descritor & Total & Filtro data de publicação & Filtro leitura dos resumos \\
\hline "Ensino Híbrido" & 30 & 22 & 4 \\
\hline \multicolumn{3}{c}{ Fonte: Elaborado pelos os autores. }
\end{tabular}

Percebeu-se que o número de trabalhos sobre o uso do Ensino Híbrido nas Ciências é bastante incipiente. Embora inicialmente a busca nos direcionou a 22 trabalhos, uma análise mais detalhada mostrou que apenas quatro trabalhos referem-se à temática proposta. A Tabela 
2 descreve os trabalhos com o título, o(s) autor(es), a revista e o ano da publicação de cada artigo.

Tabela 2- Artigos analisados

\begin{tabular}{|c|c|c|c|}
\hline Título & Autor(es) & Revista & $\begin{array}{c}\text { Ano de } \\
\text { publicação }\end{array}$ \\
\hline $\begin{array}{l}\text { Como Significar a Aprendizagem de } \\
\text { Matemática Utilizando os Modelos } \\
\text { de Ensino Híbrido }\end{array}$ & $\begin{array}{l}\text { Adriane Carrilho Esperança Vergara; } \\
\text { Verlani Timm Hinz; João Ladislau } \\
\text { Barbará Lopes }\end{array}$ & Thema & 2018 \\
\hline $\begin{array}{l}\text { Ensino Híbrido com a utilização da } \\
\text { plataforma Moodle }\end{array}$ & $\begin{array}{l}\text { Débora de Sales Fontoura da Silva } \\
\text { Frantz; Nelson Luiz Reyes Marques; } \\
\text { Janilse Fernandes Nunes; Iuri } \\
\text { Lammel Marques }\end{array}$ & Thema & 2018 \\
\hline $\begin{array}{l}\text { Ensino Híbrido em formação docente } \\
\text { de curso de Biologia em uma } \\
\text { disciplina em Instituição de Ensino } \\
\text { Superior Pública }\end{array}$ & Saulo Cezar Seiffert Santos & Educitec & 2016 \\
\hline $\begin{array}{l}\text { Modelo de Ensino Híbrido: A } \\
\text { Percepção dos } \\
\text { Metodologia em Relação à } \\
\text { Metodologia Tradicional }\end{array}$ & $\begin{array}{l}\text { João Batista da Silva, Diego de } \\
\text { Oliveira Silva, Gilvandenys Leite } \\
\text { Sales }\end{array}$ & $\begin{array}{l}\text { Conhecimento } \\
\text { Online }\end{array}$ & 2018 \\
\hline
\end{tabular}

Fonte: Elaborado pelos autores.

Ao observar a Tabela 2 identificamos que as produções são bastante recentes, sendo três delas do ano de 2018. Ainda cabe destacar que dois trabalhos são publicados na mesma Revista. Para realizar a análise dos quatro artigos encontrados foi feita a leitura do texto completo, revelando que as quatro produções abordam a temática Ensino Híbrido em diferentes perspectivas.

Nesse sentido, com o objetivo de identificar $e$ analisar as produções científicas que tiveram como tema o Ensino Híbrido nas Ciências, publicadas nos últimos seis anos e disponíveis no Portal de Periódicos da CAPES, a terceira etapa, de reconhecimento/análise, faz uma escrita descritiva dos quatro artigos evidenciados, destacando o título, os objetivos, o público-alvo, a metodologia e os resultados. De acordo com Biembengut:

a partir dessa seleção, passamos a tomar ciência desses trabalhos e a situar conhecimentos relevantes para a elucidação do problema que pretendemos investigar. Não se trata apenas de levantar as pesquisas existentes e relatá-las como parte de sequência histórica linearmente trabalhada, mas, sim, identificar os pontos relevantes ou significativos que nos valham como guia para compreender os segmentos já pesquisados e expressos de forma a nos permitir elaborar um sistema de explicação ou de interpretação (BIEMBENGUT, 2008, p. 93).

O trabalho de Vergara, Hinz e Lopes (2018), intitulado Como Significar a Aprendizagem de Matemática Utilizando os Modelos de Ensino Híbrido apresentou como tema motivador o interesse na pesquisa e reflexão acerca da educação contemporânea. $\mathrm{O}$ 
objetivo do estudo "é descrever a experiência do uso do modelo Laboratório Rotacional e responder quais as estratégias e práticas pedagógicas devem ser abordadas, dentro do Ensino Híbrido, para promover a aprendizagem significativa em Matemática no Ensino Fundamental da rede pública" (VERGARA; HINZ; LOPES, 2018, p. 886). O público-alvo ou sujeitos da pesquisa foram estudantes do $8^{\circ}$ ano de uma escola pública da cidade de Pelotas, alguns professores e os gestores da instituição e foi utilizada a Plataforma Khan Academy.

Segundo os autores, a pesquisa caracterizou-se como exploratória e descritiva. Para registrar os detalhes da experiência os participantes responderam formulários baseados no Modelo de Aceitação de Tecnologia. Os formulários foram disponibilizados aos sujeitos da pesquisa por meio de documento na $W e b$, onde os pesquisados tiveram a oportunidade de expor seu ponto de vista acerca do uso das tecnologias que viabilizam o Ensino Híbrido. As alternativas de resposta foram baseadas na Escala de Likert, na qual os entrevistados especificaram seu nível de concordância com as afirmações que estivessem de acordo com os objetivos da pesquisa, em consonância com a análise e observação (VERGARA; HINZ; LOPES, 2018).

Responderam ao formulário quinze estudantes, três professores e quatro gestores, que de forma direta e indireta utilizaram o Laboratório Rotacional. A análise documental baseouse na verificação dos resultados e nos gráficos apresentados dentro da Plataforma Khan Academy, que analisa a frequência de uso, desempenho e resultado dos estudantes.

Os autores concluíram que os resultados obtidos apontam que as aulas com apoio das tecnologias digitais, apresentam-se aos professores como uma nova forma de ensinar e aos alunos uma nova forma de aprender, por meio da utilização da metodologia do Ensino Híbrido (VERGARA; HINZ; LOPES, 2018).

O artigo de Frantz et al (2018), intitulado Ensino Híbrido com a utilização da plataforma Moodle, surgiu de um trabalho motivado a partir da disciplina Tecnologia de Informação e Comunicação no ensino de Ciências e Matemática, que os autores frequentaram no curso de Doutorado em Ensino de Ciências e Matemática da Universidade Franciscana. Segundo os autores:

O desenvolvimento desse trabalho teve como objetivo evidenciar uma experiência com o uso de metodologias ativas em um ensino híbrido, mediadas por Tecnologias Digitais (TDs). A proposta envolve quatro estudantes da turma do oitavo semestre, da disciplina de Mecânica Analítica, do currículo de Licenciatura em Física do Instituto Federal Sul-rio-grandense - Campus Pelotas Visconde da Graça. Nesse trabalho, objetiva-se descrever como se deu a escolha do recurso tecnológico Moodle como recurso pedagógico e o desenvolvimento de uma atividade híbrida, tendo como base um modelo pedagógico de Educação a Distância (FRANTZ et al, 2018, p.1176). 
Relataram, também, que devido ao baixo rendimento da primeira parte do conteúdo, Mecânica Lagrangeana, apresentada de forma tradicional, foi desenvolvido um modelo de ensino no formato sala de aula invertida. A proposta abrangia a revisão dos conteúdos já estudados, além da Mecânica Hamiltoniana. Desta forma, antes de cada aula presencial, a turma teve disponível no Ambiente Virtual de Aprendizagem (AVA) da disciplina o conteúdo teórico, como conceitos, definições e propriedades, por meio de livros e vídeo-aulas selecionadas pelo professor da disciplina.

Em sala de aula, os estudantes intensificaram seus esforços na resolução de exercícios e problemas de aplicação propostos pelo professor. O papel do docente em aula foi o de orientador, auxiliando nas dúvidas do grupo em relação aos conceitos estudados em casa. Após a utilização do modelo híbrido para a revisão da Mecânica Lagrangeana, foi aplicado um instrumento de avaliação, no qual foi possível verificar a significativa melhora no aproveitamento dos estudantes. O mesmo aconteceu para o novo conteúdo, Mecânica Hamiltoniana, para o qual foi utilizada a sala de aula invertida.

Depois de quatro semanas, foi proposto aos estudantes, que em dupla, resolvessem dois exercícios e, após a correção, filmassem as soluções com as devidas explicações para ser disponibilizadas na rede. Na sequência foi realizada uma avaliação presencial e sem nenhum tipo de consulta. Segundo os autores, o aproveitamento foi surpreendente quando comparado com as turmas anteriores. Estas apresentavam um aproveitamento médio de $46 \%$ no conteúdo Mecânica Hamiltoniana e, após a aplicação da proposta híbrida, o rendimento médio passou para 70\%, aproximadamente (FRANTZ et al, 2018).

O trabalho intitulado Ensino Híbrido em formação docente de curso de Biologia em uma disciplina em Instituição de Ensino Superior Pública, de Seiffert-Santos (2016. p.5) teve como objetivo "compreender a formação didática em Biologia para licenciandos, pela reflexão teórica pedagógica, em um pensamento didático crítico sobre sua prática com perspectiva de descristianização do conhecimento biológico, por meio do Ensino Híbrido".

O público-alvo de sua pesquisa foram os estudantes do curso de Licenciatura em Ciências Biológicas de uma universidade pública na cidade de Manaus, onde foi realizada uma abordagem qualitativa do tipo estudo de caso. A pesquisa concentrou-se no caso particular da disciplina Instrumentação para o Ensino de Biologia, nos anos de 2013 e 2014, com 21 estudantes. Os dados foram coletados e analisados a partir da observação e análise qualitativa das atividades entregues pelos alunos (SEIFFERT-SANTOS, 2016).

$\mathrm{O}$ autor relata que "foram propostas nestas disciplinas as seguintes atividades com suporte de TIC's: a) Uso de WebQuest; b) Análise do Perfil Pedagógico; c) Elaboração de 
resenhas; d) Elaboração de propostas didáticas, e; e) Memorial Pessoal como Prova Final" (SEIFFERT-SANTOS, 2016, p.6).

O Ensino Híbrido foi utilizado por meio de recursos de aulas tradicionais misturado com virtuais, tais como sites, e-mail, vídeos, recursos de manipulação e interação nas aulas presenciais. Segundo o autor, estes recursos podem ser usados fora da sala de aula, como ciberespaço não formal. Dessa forma, foi observado a necessidade de reaprender conteúdos numa lógica em relação a integração entre teoria e prática no ensino. "Seria um reaprender do conteúdo, aprender a pensar como educador" (SEIFFERT-SANTOS, 2016, p.14).

O artigo intitulado Modelo de Ensino Híbrido: A Percepção dos Alunos em Relação à Metodologia Progressista x Metodologia Tradicional, de Silva, Silva e Sales (2018) teve como objetivo "aplicar uma metodologia progressista, que integra ensino presencial e online, denominada ensino híbrido, e investigar qual a percepção dos alunos sobre essa metodologia" (p.107). O público-alvo da pesquisa foram alunos de uma turma de primeiro ano do Ensino Médio do Instituto Federal de Educação, Ciência e Tecnologia do Ceará (IFCE).

Os autores desenvolveram uma pesquisa de natureza qualitativa, realizando um estudo de caso para investigar, de forma empírica, a observação de um dado fenômeno em seu contexto real. A investigação utilizou um questionário para coleta de dados, cujas questões pretendiam favorecer a expressão argumentativa por parte dos estudantes. Foram entrevistados 35 alunos com idades entre 14 e 16 anos, durante o segundo semestre de 2016. O questionário foi composto por vinte questões agrupadas em quatro categorias conceituais. São elas:

a) ao perfil do professor, sua pontualidade, assiduidade e domínio do conteúdo ensinado; b) às metodologias de ensino/aprendizagem empregada pelos professores como: métodos de ensino, compreensão dos conteúdos abordados e recursos didáticos utilizados pelo professor; c) à interação professor-aluno: incentivo à participação dos alunos e respeito; d) ao processo avaliativo: nível de avaliação adequado e métodos de avaliação. (SILVA; SILVA; SALES, p.111, 2018)

Os professores que participaram da pesquisa eram da área de Física. Todas as aulas foram presenciais com algumas atividades online, contando com a participação de dois professores, denominados de Professor A e Professor B, sendo o conteúdo separado em duas fases, e cada etapa sob a responsabilidade de um professor. Na primeira etapa, o Professor A ministrou as aulas utilizando-se de metodologias progressistas, nesse caso o Ensino Híbrido, através dos recursos didáticos: computadores, projetor, AVA, Objeto de Aprendizagem (OA), quizzes, fórum de discussões, atividades experimentais, quadro, pincel e listas de exercícios. A segunda etapa foi ministrada pelo Professor B, que usou ensino tradicional no ensino do 
conteúdo específico de Física. A metodologia foi voltada para a formalização matemática e para a resolução de exercícios, hierarquizado por graus de dificuldade, seguindo a lógica sequencial do livro didático (SILVA; SILVA; SALES, 2018).

Depois da aplicação do método proposto e dos recursos tecnológicos usados, foram analisadas as respostas fornecidas pelos estudantes sobre suas concepções sobre as metodologias, nas quais os resultados apontaram que, para a maior parte dos alunos, "o uso da tecnologia digital não é necessário para melhorar a compreensão dos conteúdos de Física. Ademais, eles acreditam que compreendem melhor o conteúdo com aulas teóricas, preferindo assim, o modelo de ensino tradicional ao invés do modelo de ensino híbrido" (SILVA; SILVA; SALES, p.103, 2018).

\section{Conclusão}

Esta pesquisa teve como objetivo mapear as produções referentes ao uso do Ensino Híbrido na área das Ciências, identificados no Portal de Periódicos da Capes, no período compreendido entre 2013 a 2018. O estudo mostrou que as produções sobre a mencionada temática foram pouco abordadas nos periódicos vinculados à CAPES. Foram apenas quatro trabalhos que versaram sobre práticas educacionais usando o Ensino Híbrido.

Devido ao pequeno número de trabalhos encontrados, não foi feita uma categorização e sim uma escrita descritiva dos quatro artigos evidenciados, detendo-se a destacar o título, os objetivos, o público-alvo, a metodologia e os resultados. Dentre os artigos descritos, dois trabalhos foram propostos por pesquisadores da região Sul, na mesma revista, um trabalho por pesquisadores da região Nordeste e um trabalho por pesquisador da região Norte.

A análise dos resumos dos artigos selecionados mostrou que a utilização do ensino híbrido pode contribuir para uma liberdade de escolha por parte dos estudantes, sobre as melhores ferramentas e formas para a construção de seu conhecimento. Destaca-se, também, que quase a totalidade dos pesquisadores defendem que as aulas com apoio das tecnologias digitais oferecem uma nova maneira de ensinar e aprender. Além disso, foi observado também a necessidade de reaprender conteúdos numa lógica que integra teoria e prática no ensino.

Entretanto, um dos artigos evidenciou que na avaliação da maioria dos estudantes, o uso das tecnologias digitais não é essencial para melhorar a compreensão dos conteúdos de Física. Além disso, eles admitiram que compreendem melhor o assunto com aulas teóricas, preferindo assim, o modelo de ensino tradicional ao invés do modelo de ensino híbrido. 


\section{Referências}

BIEMBENGUT, M. S. Mapeamento na pesquisa educacional. Rio de Janeiro: Ciência Moderna, 2008.

FRANTZ, D. S. F. S.; NUNES, J. F.; MARQUES, I. L. Ensino híbrido com a utilização da plataforma Moodle. Revista Thema, v. 15, n. 3, p. 1175-1186. 2018. ISSN 2177-2894. Disponível em: https://doi.org/10.15536/thema.15.2018.1175-1186.1070. Acesso em: 30 dez. 2018.

HORN, M. B.; STAKER, H. Blended. Usando a inovação disruptiva para aprimorar a educação. Porto Alegre: Penso, 2015. 292 p.

SEIFFERT-SANTOS, S. C. Ensino Híbrido em formação docente de curso de Biologia em uma disciplina em Instituição de Ensino Superior Pública. Revista de Estudos e Pesquisas sobre Ensino Tecnológico (EDUCITEC), v. 2, n. 4, p. 1-15. 2016. ISSN: 2446-774X. Disponível em: https://doi.org/10.31417/educitec.v2i04.134. Acesso em: 30 dez. 2018.

SILVA, J. B.; SILVA, D. O.; SALES, G. L. Modelo de Ensino Híbrido: A Percepção dos Alunos em Relação à Metodologia Progressista x Metodologia Tradicional. Revista Conhecimento Online, v. 2, a 10, p. 102-118. jul./dez. 2018. ISSN 2176-8501. Disponível em: https://doi.org/10.25112/rco.v2i0.1318. Acesso em: 30 dez. 2018.

VERGARA, A. C. E.; HINZ, V. T.; LOPES, J. L. B. Como Significar a Aprendizagem de Matemática Utilizando os Modelos de Ensino Híbrido. Revista Thema, v. 15, n. 3, p. 885904. 2018. ISSN 2177-2894. Disponível em: https://doi.org/10.15536/thema.15.2018.885904.962. Acesso em: 27 dez. 2018. 